\title{
Resistance of Staphylococcus aureus to sulphamethoxazole and trimethoprim
}

\author{
L. S. NAKHLA \\ From the Cross-Infection Reference Laboratory, Colindale, London
}

SYNOPSIS Strains of Staphylococcus aureus isolated from the lesions of hospital patients were surveyed for resistance to sulphamethoxazole and to trimethoprim. Of 675 strains tested, $18.5 \%$ were resistant to sulphamethoxazole and $1.6 \%$ to trimethoprim. All the trimethoprim-resistant strains were resistant to sulphamethoxazole and to a 1:20 mixture of the two drugs. Trimethoprimresistant strains were on average more resistant to sulphamethoxazole than were trimethoprimsensitive strains. They were all resistant to several other antimicrobial agents. Most of them had the phage-typing pattern $84 / 85,84$, or 85 .

Trimethoprim,2,4-diamino(2,3,5-trimethoxybenzyl) pyrimidine, and sulphamethoxazole came into general therapeutic use as a mixture in 1969 (Garrod and O'Grady, 1971). Favourable reports have appeared of their effect in chronic chest infections (Hughes, 1969) and in urinary-tract infections (Brumfitt, Faiers, Pursell, Reeves, and Turnbull, 1969; O'Grady, Chamberlain, Stark, Cattell, Sardeson, Kelsey, Fry, Spiro, and Waters, 1969). Garrod (1969) has suggested that they may be useful in the treatment of staphylococcal infections of the respiratory tract, and Craven, Pugsley, and Blowers (1970) advocated their use in cases of acute osteomyelitis due to penicillin-resistant staphylococci. Combined therapy with trimethoprim and sulphamethoxazole is now widely used in hospitals, and it therefore seemed desirable to find out whether a problem with resistance to these drugs was likely to appear. We therefore examined a collection of strains collected from septic lesions in hospital patients in the London area between September 1970 and October 1971.

\section{Materials and Methods}

STAPH YLOCOCCI

Each year since 1961, the Cross-Infection Reference Laboratory has received sets of 100 consecutively isolated cultures of Staphylococcus aureus from the lesions of patients in six to eight hospitals in the London area. The 1970-71 collection, from seven of

Received for publication 4 May 1972. these hospitals, was used in the present survey. After the removal of duplicate isolates from the same patient, strains that may not have been obtained from staphylococcal lesions and others not qualifying for inclusion, we were left with 675 cultures. On receipt, the strains were subcultured from single colonies, stored on nutrient agar slopes at room temperature, and phage typed and tested for resistance to antibiotics in batches.

\section{SULPHAMETHOXAZOLE AND TRIMETHOPRIM SENSITIVITY TESTS}

\section{Media}

Diagnostic sensitivity test agar (DST, Oxoid) with the addition of $5 \%$ lysed horse blood was used in tests for resistance to sulphamethoxazole and trimethoprim and to the mixture of the two drugs.

\section{Inoculum}

A 1 in 250 dilution of an 18-hour broth culture was used. This diluted culture when spread on a plate gave a growth which was just short of being confluent .

Determination of the Minimum Inhibitory Concentration (MIC)

Doubling dilutions of the drugs were incorporated into the medium, which was then poured in measured $25 \mathrm{ml}$ amounts into $9 \mathrm{~cm}$ plastic petri dishes. The range of final concentrations, in $\mu \mathrm{g}$ per $\mathrm{ml}$, were for sulphamethoxazole 3280 to $\mathbf{0 . 8}$ and for trimethoprim from 4 to 0.015 . In tests with the mixture the ratio of trimethoprim to sulphamethoxazole was $1: 20$ and 
the range was from $2+40$ to $0.015+0.3$ of the respective drugs. Drops $\left(0.01 \mathrm{ml}\right.$, about $2 \times 10^{4}$ organism per drop) of the diluted inoculum were spotted on the plates of medium by means of a multiple inoculator, 25 cultures per plate. The plates were left with the lids open to dry for 30 minutes and then incubated at $37^{\circ} \mathrm{C}$ for 18 hours. The MIC was taken as the lowest concentration that completely inhibited the growth. All strains found to be resistant to $4 \mu \mathrm{g}$ per $\mathrm{ml}$ of trimethoprim were retested in concentrations up to $256 \mu \mathrm{g}$ per $\mathrm{ml}$ of trimethoprim.

\section{Disk-diffusion sensitivity tests}

The diluted cultures were spread on plates by means of cottonwool-tipped swabs (Garrod and Waterworth, 1971). Paper disks, $6 \mathrm{~mm}$ in diameter, containing the following concentrations per disk were applied: sulphamethoxazole $50 \mu \mathrm{g}$; trimethoprim $2 \cdot 5 \mu \mathrm{g}$; sulphamethoxazole $25 \mu \mathrm{g}+$ trimethoprim $0 \cdot 15 \mu \mathrm{g}$. The plates were incubated for 18 hours at $37^{\circ} \mathrm{C}$ and the diameters of zones of inhibition were measured with calipers.

\section{Antibiotic sensitivity tests}

These were made on plates of nutrient agar, by means of Oxoid Multodisks; the plates were incubated overnight at $37^{\circ} \mathrm{C}$. Tests for methicillin resistance were made separately, with single $10 \mu \mathrm{g}$ disks, and were incubated at $30^{\circ} \mathrm{C}$.

\section{Results}

RELATION OF MINIMUM INHIBITORY CONCENTRATION AND ZONE SIZE

The first 272 strains were examined in parallel by the plate dilution and the disk-diffusion sensitivity tests. The minimum inhibitory concentration of sulphamethoxazole for these strains covered a wide range (Fig. 1) and an arbitrary decision was taken to consider a value of $102 \mu \mathrm{g}$ per $\mathrm{ml}$ or greater as an indication of resistance. With trimethoprim on the other hand, the cultures fell clearly into two groups: 269 for which the MIC was in the range of 0.12 to $0.5 \mu \mathrm{g}$ per $\mathrm{ml}$ and three with an MIC of 4 or greater (Fig. 2).

Comparison with the results of the disk sensitivity test showed the following. All the strains classified as sulphamethoxazole sensitive (MIC $\leqslant 51 \mu \mathrm{g}$ per ml) gave zones with a diameter of $18 \mathrm{~mm}$ or more, that is to say the organisms were inhibited for a distance of $6 \mathrm{~mm}$ or more from the edge of the disk (Table I). Most of the resistant strains grew right up to the disk, but a few, for which the MIC was 102-205 $\mu \mathrm{g}$ per $\mathrm{ml}$, gave small zones with a total diameter of up to $14 \mathrm{~mm}$. Trimethoprim-sensitive strains (MIC $<1.0 \mu \mathrm{g}$ per $\mathrm{ml}$ ) all gave zones $18 \mathrm{~mm}$ or more in

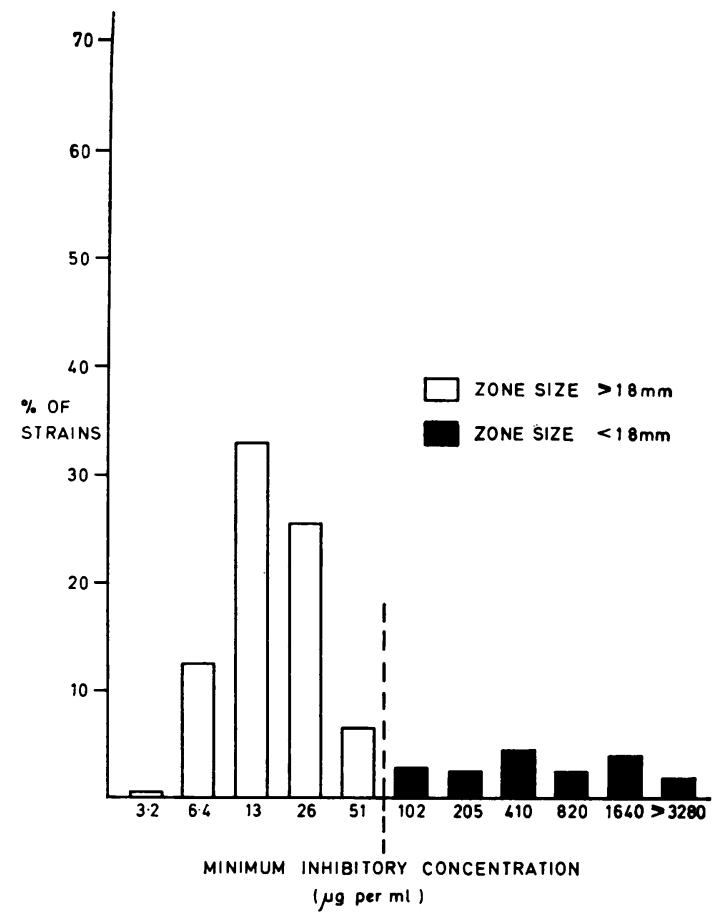

Fig. 1 Sulphamethoxazole sensitivity, MICs, and zone sizes

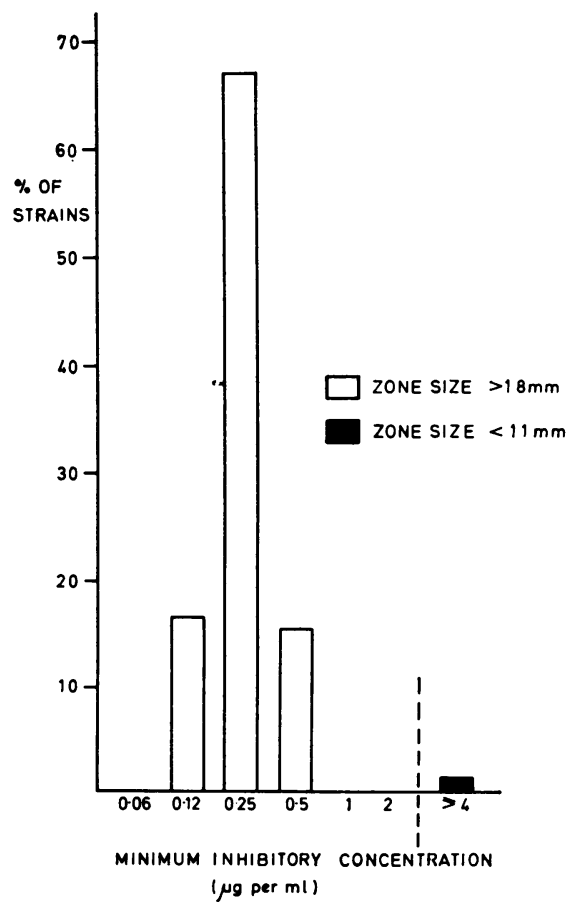

Fig. 2 Trimethoprim sensitivity, MICs, and zone sizes 


\begin{tabular}{ccll}
\hline MIC & $\begin{array}{l}\text { No. of Strains } \\
\text { Tested }\end{array}$ & $\begin{array}{l}\text { Mean Zone } \\
\text { Diameter }\end{array}$ & $\begin{array}{l}\text { Range of Zone } \\
\text { Variation }^{1}\end{array}$ \\
\hline $3 \cdot 2$ & 2 & 29 & $(28-30)$ \\
$6 \cdot 4$ & 34 & 26 & $(24-30)$ \\
13 & 96 & 24 & $(18-30)$ \\
26 & 70 & 22 & $(18-26)$ \\
51 & 18 & 21 & $(18-24)$ \\
102 & 8 & 10 & $(6-14)^{2}$ \\
205 & 9 & 7 & $(6-14)^{3}$ \\
410 & 12 & 6 & 6 \\
820 & 7 & 6 & 6 \\
1640 & 11 & 6 & 6 \\
3280 & 5 & 6 & \\
Total & 272 & & \\
\hline
\end{tabular}

Table I Sulphamethoxazole sensitivity: minimum inhibitory concentrations and zone diameters in disk test

'Disk diameter $6 \mathrm{~mm}$.

${ }^{2}$ Five of eight strains grew up to the disk edge.

'Six of nine strains grew up to the disk edge.

diameter (Table II). Of the three resistant strains two (with MICs of 8 and $16 \mu \mathrm{g}$ per ml respectively) grew to within $2.5 \mathrm{~mm}$ from the edge of the disk and one (MIC $8 \mu \mathrm{g}$ per $\mathrm{ml}$ ) gave a zone of total diameter of $11 \mathrm{~mm}$.

\begin{tabular}{lcll}
\hline MIC & $\begin{array}{l}\text { No. of Strains } \\
\text { Tested }\end{array}$ & $\begin{array}{l}\text { Mean Zone } \\
\text { Diameter }\end{array}$ & $\begin{array}{l}\text { Range of Zone } \\
\text { Variation }\end{array}$ \\
\hline 0.125 & 45 & 23 & $(20-28)$ \\
0.25 & 182 & 24 & $(18-29)$ \\
0.5 & 42 & 22 & $(18-27)$ \\
1.00 & - & - & - \\
2.00 & 3 & - & $(6-11)^{2}$ \\
4.00 & 272 & 8 & \\
Total & & & \\
\hline
\end{tabular}

Table II Trimethoprim sensitivity: minimum inhibitory concentrations and zone diameters in disk test

${ }^{1}$ Disk diameter $6 \mathrm{~mm}$.

${ }^{2}$ Two of the three strains grew up to the disk edge.

FREQUENCY OF RESISTANCE

We therefore took a zone diameter of less than 18 $\mathrm{mm}$ as an indication of resistance to each of the drugs, and examined the remaining $\mathbf{4 0 5}$ cultures. Applying this criterion to the 675 strains, $18.5 \%$ were resistant to sulphamethoxazole and $1.6 \%$ to trimethoprim. All the trimethoprim-resistant strains were also sulphamethoxazole resistant (Table III).

The strains had also been tested for resistance to 11 antibiotics, and it was apparent that the relation of trimethoprim and of sulphamethoxazole resistance to antibiotic resistance was somewhat different. Only $4 \%$ of the 134 strains that were sensitive to all antibiotics, and only $6 \%$ of the 376 strains that were resistant only to penicillin were sulphonamide ${ }^{\infty}$ resistant and in neither group were any resistant to $\vec{\circ}$ trimethoprim. Among the 165 strains that were $\vec{\sqcup}$ resistant to streptomycin, tetracycline, chloram- $\omega$ phenicol, erythromycin, oleandomycin, or novobiocin or to any combination of these, with or without penicillin resistance, $60 \%$ were resistant to or sulphamethoxazole and $7 \%$ to trimethoprim. Thus sulphamethoxazole resistance is in the main and ${ }_{\infty}$ trimethoprim resistance is entirely to be found among 0 'hospital' multiple-resistant staphylococci.

Table IV shows the frequency of sulphonamide and trimethoprim resistance among cultures from each of the seven hospitals. The percentage of sulphon- $\frac{D}{\omega}$ amide-resistant strains ranged between 13 and $30 \%$ and one or more trimethoprim-resistant strains were $\varphi$ detected in the collection of each of six of the seven ? hospitals.

\begin{tabular}{|c|c|c|c|}
\hline \multirow[t]{2}{*}{ Hospital } & \multirow{2}{*}{$\begin{array}{l}\text { No. of Strains } \\
\text { Tested }\end{array}$} & \multicolumn{2}{|c|}{ Percentage of Strains Resistant to } \\
\hline & & Sulphamethoxazole $T$ & Trimethoprim \\
\hline $\begin{array}{l}\mathbf{A} \\
\mathbf{B} \\
\mathbf{C} \\
\mathbf{D} \\
\mathbf{E} \\
\mathbf{F} \\
\mathbf{G}\end{array}$ & $\begin{array}{r}100 \\
100 \\
85 \\
98 \\
98 \\
99 \\
95\end{array}$ & $\begin{array}{l}15 \\
20 \\
13 \\
30 \\
22 \\
14 \\
17\end{array}$ & $\begin{array}{l}1 \cdot 0 \\
1 \cdot 0 \\
1 \cdot 2 \\
3 \cdot 0 \\
1 \cdot 0 \\
4 \cdot 0 \\
0\end{array}$ \\
\hline Total & 675 & 19 & $1 \cdot 6$ \\
\hline
\end{tabular}

Table IV Frequency of sulphamethoxazole and trimethoprim resistance of Staph. aureus strains from seven hospitals

Table $\mathrm{V}$ gives further information about the 11 trimethoprim-resistant cultures. The minimum inhibitory concentration of trimethoprim ranged from $N$

\begin{tabular}{|c|c|c|c|c|}
\hline \multirow[t]{2}{*}{ Resistance to Other Antibiotics } & \multirow{2}{*}{$\begin{array}{l}\text { No. of Strains } \\
\text { Tested }\end{array}$} & \multicolumn{3}{|c|}{ Percentage of Strains Sensitive or Resistant to Su and TM } \\
\hline & & $\begin{array}{l}\text { Su Sensitive } \\
T M \text { Sensitive }\end{array}$ & $\begin{array}{l}\text { Su Resistant } \\
\text { TM Sensitive }\end{array}$ & $\begin{array}{l}\text { Su Resistant } \\
\text { TM Resistant }\end{array}$ \\
\hline $\begin{array}{l}\text { Sensitive to all antibiotics } \\
\text { Resistant to penicillin only } \\
\text { Resistant to other antibiotics }\end{array}$ & $\begin{array}{l}134 \\
376 \\
165\end{array}$ & $\begin{array}{l}96 \\
94 \\
40\end{array}$ & $\begin{array}{r}4 \\
6 \\
53\end{array}$ & $\begin{array}{l}0 \\
0 \\
7\end{array}$ \\
\hline Total & 675 & $81 \cdot 5$ & $17 \cdot 0$ & 1.6 \\
\hline
\end{tabular}

Table III Relation of sulphamethoxazole (Su) and trimethoprim (TM) sensitivity to antibiotic sensitivity

${ }^{1}$ To streptomycin, tetracycline, chloramphenicol, erythromycin, novobiocin, oleandomycin, or any combination of these with or without resist ance to penicillin. 


\begin{tabular}{|c|c|c|c|c|c|c|}
\hline \multirow{2}{*}{$\begin{array}{l}\text { Strain } \\
\text { No. }\end{array}$} & \multirow[t]{2}{*}{ Resistance Pattern } & \multirow[t]{2}{*}{ Hospital } & \multicolumn{3}{|c|}{ Minimum Inhibitory Concentration ( $\mu \mathrm{g}$ per $\mathrm{ml}$ ) } & \multirow{2}{*}{$\begin{array}{l}\text { Phage } \\
\text { Typing } \\
\text { Pattern }\end{array}$} \\
\hline & & & $T M$ & $T M+S u$ & Su & \\
\hline $\begin{array}{r}1 \\
2 \\
3 \\
4 \\
5 \\
6 \\
7 \\
8 \\
9 \\
10 \\
11\end{array}$ & 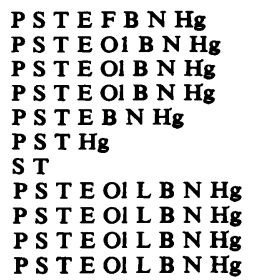 & $\begin{array}{l}\text { A } \\
\text { B } \\
\text { C } \\
\text { D } \\
\text { D } \\
\text { D } \\
\text { E } \\
\text { F } \\
\text { F } \\
\text { F } \\
\text { F }\end{array}$ & $\begin{array}{r}8 \\
8 \\
16 \\
64 \\
16 \\
128 \\
16 \\
32 \\
16 \\
8 \\
32\end{array}$ & $\begin{array}{l}4+80 \\
2+40 \\
2+40 \\
8+160 \\
4+80 \\
8+160 \\
4+80 \\
8+160 \\
8+160 \\
4+80 \\
8+160\end{array}$ & $\begin{array}{r}1640 \\
1640 \\
1640 \\
3280 \\
1640 \\
1640 \\
820 \\
1640 \\
1640 \\
1640 \\
1640\end{array}$ & $\begin{array}{l}84 / 85 \\
85 \\
\text { NT } \\
85 \\
85 \\
\text { NT } \\
\text { NT } \\
84 \\
84 \\
84 \\
84\end{array}$ \\
\hline
\end{tabular}

Table V Characters of strains resistant to trimethoprim and sulphonamide
$\mathbf{P}=$ penicillin
$\mathrm{OI}=$ oleandomycin
$\mathbf{S}=$ streptomycin
$\mathbf{L}=$ lincomycin
$\mathrm{N}=$ neomycin
TM $=$ trimethoprim
$\mathbf{T}=$ tetracycline
$\mathbf{F}=$ fucidin
$\mathrm{Su}=$ sulphonamide
$\mathbf{E}=$ erythromycin
B $=$ bacitracin
NT = untypable

8 to $128 \mu \mathrm{g}$ per ml. Their resistance to sulphamethoxazole was distinctly greater than that of the average trimethoprim-sensitive strains. Ten of 11 trimethoprim-resistant strains, but only 16 of 49 trimethoprim-sensitive, sulphamethoxazole-resistant strains, grew in the presence of $1640 \mu \mathrm{g}$ per $\mathrm{ml}$ or more of sulphamethoxazole. All were multiple-antibiotic resistant. All but one were resistant to penicillin and all the penicillin resistant strains were mercury resistant. The number of strains resistant to other antibiotics were: streptomycin 11, tetracycline 11, erythromycin nine, oleandomycin, neomycin, and bacitracin eight, lincomycin four, and fucidin one. Eight of the 11 strains had the phage-typing pattern $84 / 85,84$, or 85 , and three were untypable. None of the cultures hydrolysed Tween 80 .

The trimethoprim-resistant cultures from hospital $F$ were identical in phage-typing pattern and in antibiogram; two of the cultures of hospital $D$ had a similar phage typing pattern but were different in antibiotic-resistance pattern, and the third culture was distinct.

The MICs of a 1:20 mixture of the two drugs for the 11 trimethoprim-resistant strains, although lower than that of either drug alone, arestill too high for the combination to be of therapeutic value (Table V). The peak plasma level after a $100 \mathrm{mg}$ of trimethoprim is 0.9 to $1.2 \mu \mathrm{g}$ per $\mathrm{ml}$, of which $42.46 \%$ is protein bound. After a $2 \mathrm{~g}$ dose of sulphonamide it is $100 \mu \mathrm{g}$, of which up to $98 \%$ can be protein bound (Garrod and O'Grady, 1971).

\section{Discussion}

The resistance of Staphylococcus aureus to sulphamethoxazole and trimethoprim does not appear to have been reported before. Resistance to sulphonamides alone has been recognized for many years, though few recent surveys of its frequency have been reported. Goldie, Alder, and Gillespie (1971) examined a small sample of strains isolated in 1969 and 1970, and reported sulphonamide resistance in $5 \%$ of strains from patients outside hospital and $40 \%$ of strains from hospital patients. They did not observe resistance to trimethoprim. It is not known whether trimethoprim-resistant strains of staphylococci existed naturally before the drug came into use, or whether the resistance has arisen spontaneously and been selected since. The fact that it has now been found only in multiple-antibiotic-resistant strains of types known to be endemic in hospitals suggests the latter. The frequent use of trimethoprim in combination with sulphamethoxazole for the treatment of infections of the urinary and respiratory tracts in hospital patients has resulted in the exposure to selection by trimethoprim of large numbers of Staph. aureus strains that are already sulphonamide resistant. Trimethoprim-resistant variants of coliform bacilli are easily selected in vitro (Darrell, Garrod, and Waterworth, 1968) and strains resistant to both drugs have been isolated from patients after combined therapy (Lacey, Gillespie, Bruten, and Lewis, 1972).

Most of our trimethoprim-resistant staphylococci were lysed by phage 84 or phage 85 , or by both phages. They thus belong to a group of closely related strains that first became endemic in British hospitals in 1961 (Jevons and Parker, 1964; Jevons, John, and Parker, 1966). For several years they were almost the only neomycin-resistant staphylococci, and their spread was probably associated with the extensive use of this antibiotic. It is unfortunate that trimethoprim resistance has now appeared in similar strains that are already resistant to many other antimicrobial agents. In addition to restricting further the range of drugs that can be used for the treatment of infection with these strains, this addi- 
tional resistance to a widely used drug may provide another selective advantage in hospitals for a highly undesirable staphylococcus. All the trimethoprimresistant strains we have seen so far are methicillin sensitive, though some methicillin-resistant $84 / 85$ strains were seen in earlier years.

It is clear that combined therapy with sulphamethoxazole and trimethoprim is unlikely to prevent the appearance of trimethoprim resistance in organisms, such as Staph. aureus and the enterobacteria, in which sulphonamide resistance is already common. We agree with Goldie and his colleagues (1971) that a reduction of the total exposure of the hospital population to these drugs is the only measure likely to prevent a further increase in the frequency of resistant strains.

I am deeply indebted to Dr M. T. Parker for advice and encouragement. The cooperation of hospital laboratories who provided the cultures used in this work is acknowledged with thanks. I am grateful to Mr R. G. Gibson for drawing the chart.

\section{References}

Brumfitt, W., Faiers, M. C., Pursell, R. E., Reeves, D. S., and Turnbull, A. R. (1969). Bacteriological, pharmacological and clinical studies with trimethoprim-sulphonamide combinations wit/ particular reference to treatment of urinary infections. Postgrad:med. J., 45, Nov. Suppl., 56-61.

Craven, J. L., Pugsley, D. J., and Blowers, R. (1970). Trimethoprim心 sulphamethoxazole in acute osteomyelitis due to penicilling resistant staphylococci in Uganda. Brit. med. J., 3, 201-203.

Darrell, J. H., Garrod, L. P., and Waterworth, P. M. (1968). Tri은. methoprim: laboratory and clinical studies. J. clin. Path., 21 202-209.

Garrod, L. P. (1969). The possible scope of trimethoprim-sulphonamide treatment. Postgrad. med. J., 45, Nov., Suppl. 52-55.

Garrod, L. P., and O'Grady, G. (1971). Antibiotic and Chemotherapy 3rd ed., pp. 16, 42, 47. Livingstone, Edinburgh and London.

Garrod, L. P., and Waterworth, P. M. (1971). Tests of bacterial sensitivity to drugs. Disease a Month, July, pp. 1-48.

Goldie, D. J., Alder, V. G., and Gillespie, W. A. (1971). Changes in the drug resistance of Staphylococcus aurens in a non-hospit population during a 20-year period. J. clin. Path., 24, 44-47. ?ํำ

Hughes, D. T. D. (1969). Treatment of exacerbations of chronic chesiv infections with combinations of sulphamethoxazole-trimetho prim (including comparison with ampicillin). Postgrad. med. J. 45, Nov. Suppl., 86-88.

Jevons, M. P., and Parker, M. T. (1964). The evolution of new hos pital strains of Staphylococcus aureus. J. clin. Path., 17, 2430
250 .

Jevons, M. P., John, M., and Parker, M. T. (1966). Cultural charac $=-$ ters of a newly recognized group of hospital staphylococci. $J \mathbb{Z}$ clin. Path., 19, 305-312.

Lacey, R. W., Gillespie, W. A., Bruten, D. M., and Lewis, E. LE

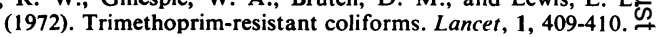

O'Grady, F., Chamberlain, D. A., Stark, J. E., Cattell, W. R. $\overrightarrow{0}$ Sardeson, J. M., Fry, I. K., Spiro, F. I., and Waters, A. H (1969). Long-term, low-dosage, trimethoprim-sulphonamide in the control of chronic bacteriuria. Postgrad. med. J., 45, Nov Suppl., 61-64. 